\title{
A review of research on the Job Characteristics Model and the attendant job diagnostic survey
}

\author{
Billy Boonzaier*, Bernhard Ficker \& Braam Rust \\ Faculty of Management, Cape Technikon, PO Box 652, Cape Town, Republic of South Africa \\ Email: billy@ctech.ac.za \\ Received October 2000
}

\begin{abstract}
The Job Characteristics Model is widely accepted as a conceptual tool for addressing problems related to employee demotivation, dissatisfaction and marginal performance. The validity of the Job Characteristics Model (Hackman \& Oldham, 1980) was assessed by reviewing relevant studies of the model. The review and evaluation is based on studies which test the variables and the relationships between variables as contained in the model. The evidence confirms that the dimensionality of the job characteristics is best represented by the five-factor solution as proposed by the model. The subjective self-report measures of the five job characteristics as formulated by the theory and measured by the revised Job Diagnostic Survey (JDS) are also supported. No evidence was found for the multiplicative Motivating Potential Score (MPS) and as a result the use of a simple additive index of job complexity is recommended as predictor of personal and work outcomes. Strong empirical support exists for the relationships between the job characteristics and the personal outcomes. Strong relationships between the job characteristics and the work outcomes, however, fail to materialize. Results fail to support the mediating effect of psychological states on the job characteristics/outcomes relationships as specified by the model. The postulated relationships between job characteristics and psychological states are also not confirmed by empirical evidence. The role of growth-need strength, knowledge and skill, and work environment characteristics as moderators of the relationships between job characteristics and psychological states, as well as the relationships between psychological states and personal and work outcomes, are seriously questioned. Directions for future research on the Job Characteristics Model and the attendant Job Diagnostic Survey are proposed.
\end{abstract}

\section{Introduction}

\section{The Job Characteristics Model of job redesign}

Hackman and Lawler are considered the fathers of the original job characteristics theory (Miner, 1980: 230). The job characteristics theory of Hackman and Lawler (1971) was formulated as a model of job redesign. Hackman and Oldham $(1974,1980)$ subsequently revised the job characteristics theory and termed their refinement the Job Characteristics Model, henceforth referred to as the model, which is now considered the most influencial model guiding research on the nature or characteristics of jobs (Johns, Xie \& Fang, 1992: 658). Kelly (1992: 754) refers to this model as the most well-known and widely discussed theory of job redesign. Hackman and Oldham (1975) also developed a measuring instrument to validate their model, namely the Job Diagnostic Survey (JDS), which was revised parallel to refinements of the model (Hackman \& Oldham, 1980).

\section{Purpose of the model}

The Job Characteristics Model, the accompanying JDS and the proposed action steps for improving motivation, satisfaction and performance (Hackman \& Oldham, 1980) have been functionally utilized in South Africa as a revised job redesign practice (Wiesner \& Vermeulen, 1997: 177) to address critical human resources problems currently facing managers and human resources practitioners (Boonzaier \& Boonzaier, 1994: 101-109). More specifically, the model specifies the conditions under which workers will display motivation, satisfaction and productive behaviour. The JDS, in turn, can be used to:

- diagnose jobs considered for redesign in order to establish the current potential of a job for enhancing motivation and satisfaction;

- identify those specific job characteristics that are most in need of enrichment;

- $\quad$ assess the 'readiness' of employees to respond positively to improved jobs.

Where remedial action is required, strategic guidelines (Anthony, Perrewé \& Kacmar, 1999: 308) assist managers in planning for an enriched workplace.

The model, the attendant JDS and the proffered action steps thus facilitate a process through which managers can practically achieve an optimal fit between workers and their jobs by addressing motivation, satisfaction and performance problems caused primarily by shortcomings in the nature of jobs.

*This research was conducted as part of the doctoral dissertation of the first author, under supervision of the latter authors, to be submitted to the Cape Technikon. The financial assistance of the National Research Foundation towards this research is hereby acknowledged. 


\section{Outline of the model}

The Job Characteristics Model is underpinned by the humanistic management approach which purports to preserve, maintain and develop the 'human factor' in the workplace. This intent is visible in the various components of the model. According to the model (see Figure 1), workers exhibit positive personal and work outcomes (internal work motivation, general job satisfaction, growth satisfaction, and work effectiveness) if they experience three psychological states, namely:

- $\quad$ they perceive their work to be meaningful;

- they experience responsibility for the results or outcomes of their work;

- they have knowledge of the results of their work.

Positive reinforcement and personal reward are experienced (Armstrong, 1996: 382) when employees are aware of performing well on a task (knowledge of results) that the employee feels accountable and responsible for (experienced responsibility) and which is regarded as worthwhile and of value (experienced meaningfulness). These three psychological states are enhanced by the presence of five specific job characteristics, namely skill variety, task identity, task significance, autonomy, and feedback.

\section{Definition of variables}

Hackman and Oldham $(1975,1976)$ provide definitions of the different job characteristics, psychological states, outcomes and moderator variables. The model refers to internal work motivation as the extent to which the employee is self-motivated to perform effectively on the job, that is, the employee experiences positive internal feelings when performing effectively on the job, and negative internal feelings when doing poorly. General job satisfaction refers to the degree to which the employee is satisfied and happy with the job. Growth satisfaction refers to the degree to which an individual is satisfied with opportunities for growth in the job. This particular personal outcome is the result of elaborations on the original model by Hackman, Pearce and Wolfe (1978: 293). The model does not provide a definition of work effectiveness as this factor is unique to particular work settings.

Experienced meaningfulness of the work refers to the degree to which the employee experiences the job as generally meaningful, valuable and worthwhile. Experienced responsibility for work outcomes is defined as the degree to which the employee feels personally accountable and responsible for the results of the work (s)he does. Knowledge of results is the degree to which the employee knows and understands, on a continuous basis, how effectively (s)he is performing the job.

According to the model, for workers to experience meaningfulness, jobs must contain skill variety, task identity, and task significance. Skill variety refers to the degree to which a job requires a variety of different activities in carrying out the work, which involves the use of a number of different skills and talents of the employee. Task identity is defined as the degree to which the job requires completion of a 'whole' and identifiable piece of work - that is to say, doing a job from beginning to end with a visible outcome. Task significance represents the degree to which the job has a substantial impact on the lives or work of other people, whether in the immediate organization or in the external environment.

Workers will experience responsibility for their work outcomes if jobs contain a significant degree of autonomy. Autonomy represents the extent to which the job allows the employee substantial freedom, independence, and discretion in scheduling the work and in determining the procedures to be used in carrying it out.

For workers to have knowledge of the results of their work activities, feedback must be introduced. Feedback refers to the extent to which performing the work activities required by the job results in the employee obtaining direct and clear information from the job about the effectiveness of her or his performance.

The model further specifies the existence of moderator variables, namely growth-need strength, satisfaction with pay, satisfaction with security, satisfaction with co-workers, satisfaction with supervision, and knowledge and skill. These moderators intervene to influence both the relationships between the job characteristics and the psychological states, as well as the relationships between the psychological states and the personal and work outcomes. The moderator variables are defined as follows:

- Growth-need strength refers to workers' needs for personal accomplishment, for learning, and for developing themselves beyond where they are at present.

- Pay satisfaction refers to the degree of satisfaction with basic compensation and benefits as well as satisfaction with the extent to which the organization's compensation relates to the individual's contribution to the organization.

- Security satisfaction is the degree of satisfaction with the amount of general security experienced as well as with the prospects of security.

- Co-worker satisfaction reflects the degree of satisfaction with other workers with whom contact is made in the work situation, as well as satisfaction with opportunities to get to know and to help people.

- Supervision satisfaction refers to the degree of satisfaction with the treatment, support and guidance received from supervisors, as well as the degree to which the general quality of supervision is considered satisfactory.

- Knowledge and skill as a moderator variable is not specifically defined as they are unique to particular work settings. 


\section{Job}

Skill variety

Task identity

Task significance

Feedback

Autonomy characteristics

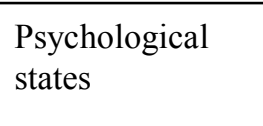

\section{Experienced}

meaningfulness

of work

\section{Experienced}

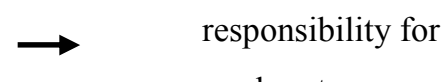

work outcomes

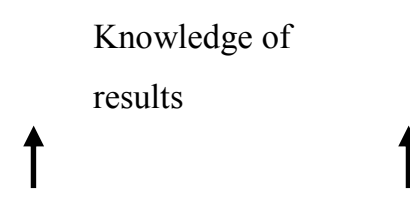

\section{Moderators}

Growth-need strength

Pay satisfaction

Security satisfaction

Co-worker satisfaction

Supervisor satisfaction

Knowledge and skill
Personal and work outcomes

High interna

work motivation

High general job

satisfaction

High growth

satisfaction

High work

effectiveness

Figure 1: The Job Characteristics Model (Hackman \& Oldham, 1980: 90)

\section{The job diagnostic survey}

The JDS provides direct measures of all the variables in the Job Characteristics Model as depicted in Figure 1 (excluding work effectiveness and knowledge and skill, as previously explained). The JDS also measures two additional job characteristics that are not included in the model (Hackman \& Oldham, 1980: 103-104), namely:

- Feedback from agents: the degree to which the employee receives clear information about his or her performance from supervisors or from co-workers.

- $\quad$ Dealing with others: the degree to which the job requires the employee to work closely with other people, inside and outside the organization, in the execution of work activities.

Feedback from agents supplements JDS information on the job characteristic variable 'feedback'. Dealing with others is designed to alert the planners of job redesign interventions to the possibility of an interconnected set of jobs requiring attention rather than focusing on a single job.

Based on the model, the JDS computes a score reflecting the overall motivating potential of a job in terms of the five job characteristics. This Motivating Potential Score (MPS) provides a single indicator of the extent to which the five job characteristics are present in a job and is computed as follows:

MPS $=\left[\frac{\text { skill var iety }+ \text { task identity }+ \text { task significance }}{3}\right]$ Xautonomy X feedback

The MPS ranges from 1 to 343 as the five job characteristics are measured on seven-point scales. 


\section{Implications of the model}

Specifically, the following theoretical statements can be inferred from the Job Characteristics Model:

- Internal work motivation, general job satisfaction, growth satisfaction, and work effectiveness result from jobs so designed as to prompt employees to experience three psychological states, namely experienced meaningfulness of their work, experienced responsibility for work outcomes, and knowledge of results.

- The presence of five job characteristics determines the experience of three psychological states. Skill variety, task identity and task significance lead to experienced meaningfulness of the job, autonomy predicts experienced responsibility for work outcomes, and feedback from the job influences knowledge of results.

- The psychological states are complete mediators of the relationships between the job characteristics (independent variables) and personal and work outcomes (dependent variables).

- The overall potential of a job to prompt internal work motivation (MPS) is determined by the mathematical product of feedback, autonomy, and the mean of skill variety, task identity and task significance. (Feedback and autonomy are thus assumed to be more critical than skill variety, task identity and task significance individually in prompting internal work motivation).

- The employee's growth-need strength, satisfaction with pay, security, supervision and co-workers, as well as the employee's level of knowledge and skill, moderate both the relationships between the job characteristics and the psychological states and the relationships between the psychological states and the personal and work outcomes.

The JDS represents a comprehensive set of measurements with which the different components of the Job Characteristics Model can be tested empirically. The theory can thus be implemented and utilized in actual job enrichment programmes (Nel, Gerber, Van Dyk, Haasbroek, Schultz, Sono \& Werner, 2001: 333-334), also in South Africa. Diagnosis of jobs prior to redesign is possible, and the effects of job enrichment interventions can be measured. The formulation of this model and instrument can be regarded as the first attempt in job redesign theory to focus on individual differences directly by measuring the critical psychological states and the growth-need strength of workers. It is, therefore, a worker-based job redesign theory.

Subsequent to the formulation of the Job Characteristics Model, studies relating to the testing of the validity of the variables and the relationships between the variables of the model were conducted. These empirical findings are reported in the following section.

\section{Assessment of the Job Characteristics Model}

The Job Characteristics Model and the JDS were formulated and compiled for the explicit purpose of job redesign efforts in industry. Of all the job redesign theories to date, the Job Characteristics Model has generated the most research and discussion (Algera, 1990: 86). The model is also regarded as one of the most comprehensive frameworks for job redesign (Anthony, Perrewé \& Kacmar, 1999: 306). The JDS, likewise, is the most widely used instrument in job redesign research and possesses known and generally acceptable psychometric properties (Griffin, 1991: 429). However, in spite of evidence supporting the validity of the Job Characteristics Model and the utility of the JDS, local and international criticism has increasingly been voiced regarding specific components of the model, and specific shortcomings of both the model and the JDS have repeatedly been documented (Wall, Clegg \& Jackson, 1978; Roberts \& Glick, 1981; Birnbaum, Farh \& Wong, 1986; Graen, Scandura \& Graen, 1986; Fried \& Ferris, 1987; Idaszak \& Drasgow, 1987; Evans \& Ondrack, 1991; Cordery \& Sevastos, 1993).

The purpose of this section is to review relevant studies regarding this model by indicating which parts of the model are supported by empirical evidence and can therefore be regarded as valid, and which parts of the model need modification. Subsequently, directions for future research on the model and accompanying JDS are proposed.

The review of studies and the evaluation of the model will be presented, firstly, in terms of the variables contained in the model and, secondly, in terms of the relationships between the variables in the model.

Review and evaluation: variables in the Job Characteristics Model

The model specifies personal and work outcomes as dependent variables and job characteristics as the independent variables.

\section{Job characteristics}

Empirical evidence relating to the job characteristics focused predominantly on the following themes:

- the factor structure of the job characteristics;

- $\quad$ subjective versus objective job characteristics;

- the additional job characteristics;

- the Motivating Potential Score (MPS).

\section{Factor structure of the job characteristics}

The Job Characteristics Model stipulates five core job characteristics (skill variety, task identity, task significance, autonomy, and feedback) as determinants of work behaviour. The original exposition of the model contained four job characteristics (Hackman \& Lawler, 1971), but Hackman and Oldham (1974, 1975, 1976, 1980) included task significance as a fifth job characteristic. Individual indicators of the extent to which each of the job characteristics are present in a job are 
provided by the JDS, in conjunction with a composite score, the MPS index, being a single indicator of overall job complexity (refer to the job diagnostic survey section for the algorithm for computing the MPS index). The question thus arises as to which particular combination of job characteristics, whether five separate or a single index, provides optimum representation of the complexity of a job.

In their factor analysis of the job characteristics, Sims, Szilagyi and Keller (1976) obtained responses from both non-supervisory employees of a medical centre and supervisory employees of a manufacturing firm. Support was found for the a priori dimensionality of five job characteristics as suggested by the model. Pokorney, Gilmore and Beehr (1980) collected data from 173 employees of a large insurance company with branches located throughout the United States and Canada. Results were consistent with the five job characteristics specified by the model. Further support for the postulated dimensionality of the job characteristics is provided by Lee and Klein (1982), using a sample of 1632 public sector workers. The study of Harvey, Billings and Nilan (1985) gives further credence to the five-factor structure of the model. Their finding is based on data from 2028 full and part-time workers of the Ohio National Guard. The study of Johns, Xie and Fang (1992), based on a random sample of 605 first and second level managers in a large utility company in Canada, also found the five-factor solution appropriate.

Dunham (1976), however, found that a single factor accounted for $83 \%$ of the explained variance in a study of 3610 employees of a large merchandising corporation, thus not supporting the five job characteristics as specified by the model. Based on an alternative factor rotation, the consideration of a four-factor solution is advised with the skill variety and autonomy items collapsing to form a common factor and thus being empirically the same. Dunham (1976) proposes, in conclusion, a single- or a four-factor structure as the most parsimonious solutions. Dunham, Aldag and Brief (1977) reported further on the factor structure of the job characteristics. The JDS data of 5945 workers from five different organizations, which was further divided into 20 subsamples, was analyzed. Results indicate an inconsistency in the dimensionality of the job characteristics across samples. The structure of five job characteristics was found in only two of the twenty samples investigated. In general, a smaller number of factor structures were found, usually four, three or two, depending on the sample.

Fried and Ferris (1986) found a three-factor structure the best alternative. A sample of 6930 employees in 56 organizations across 876 different jobs was used. A principal axis factor analysis, oblique factor rotations and a procrustes transformation were applied in the analysis of data. Results showed that task identity and feedback can be regarded as separate and distinct job characteristics, but that skill variety, task significance and autonomy collapsed into a single factor. Possible causes cited are the moderating influence of age, education and position on the underlying factor structure. For young people who are highly educated, for example, results support the a priori five-factor solution.
Idaszak and Drasgow (1987) point to the reverse-score items of the JDS as a major source of inconsistencies in determining the number of factors operating as job characteristics. The factor structures obtained when administering the original JDS, as well as a revised JDS (designed by replacing reversescore items with new items), were investigated. Factor analyses identified six dimensions underlying the original JDS. Five of the factors correspond to the pattern expected for the JDS items; the sixth was identified as a measurement factor. When the revised JDS was administered to 134 employees of a printing company, the a priori five-factor solution was obtained with no measurement factor. On this basis the researchers recommend the use of their revised JDS.

The study of Kulik, Oldham and Langner (1988) also contrasted the JDS of Hackman and Oldham (1980) with the revised version proposed by Idaszak and Drasgow (1987). A sample of 224 dairy workers completed both versions of the JDS. Results of a confirmatory factor analysis showed that job characteristics items on the revised JDS conformed more closely to the hypothesized five-factor structure than did the original JDS job characteristics items. However, with regard to practical implications, results of Lisrel analyses indicated that the revised items did not improve the usefulness of the JDS in predicting satisfaction, internal motivation or productivity. Cordery and Sevastos (1993) also compared the original and revised versions of the JDS. The sample consisted of 3044 white collar workers from departments of the Western Australian State Public Service. Results show, too, that a revised version of the JDS, using only positively worded items, better fits the five-factor structure underlying the instrument. Harvey, Billings and Nilan (1985) report the same conclusion. By contrast, Burke (1999: 218) indicates that the negatively worded items in the JDS are not as serious a concern as researchers have implicated. Rather, the feasibility of screening for invalid responses (those respondents who were careless, inattentive, sabotaging the completion of questionnaires or who read poorly) instead of changing the JDS to include only positively worded items, is highlighted.

In trying to determine the validity of using a five-factor structure, there are several problems in comparing research results:

- Different instruments (for example the Job Diagnostic Survey and the Job Descriptive Inventory) are used in different studies to measure the job characteristics, thus confounding comparisons.

- $\quad$ The nature of samples chosen differ with regard to range of jobs, organizational levels and industries included.

- $\quad$ Some studies make use of objective job characteristics (as reported by external individuals) while others use subjective measures (that is, the self-reports of job incumbents).

- Idaszak, Bottom and Drasgow (1988) outline specific methodological problems which seem to be the primary cause of inconsistent results obtained in the large number of factor analyses of the JDS. Of specific relevance is 
their finding that samples approximating 1000 subjects are needed to obtain significant results on the factor structure of the job characteristics when using an instrument like the JDS.

In conclusion, studies on the dimensionality of the job characteristics propose from a one- to a five-factor solution. Research on this issue, when using the original JDS, can thus be regarded as inconclusive. The studies of Harvey, Billings and Nilan (1985), Idaszak and Drasgow (1987), Kulik, Oldham and Langner (1988) and of Cordery and Sevastos (1993), however, provide sufficient evidence to justify using the revised version of the JDS to measure the five job characteristics. The revised JDS also supports a five-factor solution as proposed by the model. Experience in South Africa (Boonzaier \& Boonzaier, 1994) tends to favour the use of the revised JDS which is thus recommended for diagnostic purposes by researchers and practitioners alike.

\section{Subjective versus objective job characteristics}

According to Hackman and Lawler (1971), as well as Hackman and Oldham $(1974,1975,1976,1980)$, the worker's perception of the extent to which the job characteristics are present in her/his job determines the personal and work outcomes. This perception of the job characteristics is measured by the JDS and relies on the subjective evaluation by the job incumbent. The dilemma this creates is that when job redesign is introduced, the objective characteristics of jobs are altered. The question is thus whether objective changes in job characteristics result in changes in subjective job perceptions in the direction of the objective modifications. Fried and Ferris (1987) addressed this issue of the linkage between subjective and objective job characteristics in their comprehensive review of nearly 200 relevant studies of the model. In general, the studies included in this meta-analysis show that objective manipulations of jobs do result in changes in the job perceptions of workers in the direction of the objective change. The experimental study by Taber and Taylor (1990) also shows that changes in objective work tasks result in parallel changes in employee perceptions of their jobs.

Fried and Ferris (1987) also provide an indication of the link between objective and subjective job characteristics as evidenced by the correlations between the job incumbent's ratings of the extent to which job characteristics are present in her/his job and the ratings of these same jobs by other sources, for example peers, supervisors and researchers. A median of correlations of 0,63 is reported and a median of median correlations of 0,56 for 15 studies where job incumbent ratings were correlated with that of other sources. Fried and Ferris (1987) conclude that the subjectivity problems associated with incumbent-rated job characteristics are less serious than initially believed.

In a study examining the influence of 24 job characteristics on 17 dependent variables, Algera (1983) found similar correlational patterns when job characteristics were rated by job incumbents and when job characteristics were rated by non-job incumbents. Oldham, Hackman and Pearce (1976) and Stone and Porter (1978) likewise found similar correlations between job characteristics and outcome variables when subjective and objective ratings were used as independent variables. This finding implies that there is no real difference between objective and perceived or subjective job characteristics.

Substantial convergent validities between reports by job incumbents and reports by other sources such as co-workers, observers and supervisors have been reported in several other studies as well. Hackman and Oldham (1976: 261), for example, found high convergent validities between the different sources. Hackman and Lawler (1971) report convergent validities as high as 0,95. Spector and Jex (1991) also show that job characteristics based on self-reports represent a reasonable measure of objective job characteristics, based on their sample of 232 civil service employees. Kulik, Oldham and Hackman (1987: 285) state that 'employees are able to provide generally accurate assessments of the characteristics of their jobs'. Johns, Xie and Fang (1992) provide further justification for the use of subjective selfreports as evidential of the job characteristics. Furthermore, they regard the job characteristics model as the 'most influential model guiding self-report research on job characteristics' (ibid., 1992: 658). It can be argued that when the intent is to predict or understand employee behaviour at work, employee ratings of job characteristics are preferable to use, since it is an employee's own perceptions of the objective job that is causal of her/his reactions to it (Hackman \& Oldham, 1976: 261).

Conversely, Birnbaum, Farh and Wong (1986) advocate the use of multiple sources of information on job characteristics for use in job redesign interventions. Cellar, Kernan and Barrett (1985), however, question the validity of regarding observer ratings as objective indices of the job characteristics by illustrating that observers can be biased by the same factors which affect ratings by incumbents.

In conclusion, it can be stated that, in job redesign studies, the utilization of subjective job characteristics as reported by workers seems to have weathered rigorous empirical investigation. Studies reveal that the possible confounding factors, namely common method variance (Roberts \& Glick, 1981), the influence of extraneous social cues (Griffin, 1983), and priming effects (Fried \& Ferris, 1987), have been exaggerated. There is a relatively high relationship between the extent of the job characteristics present in a job as perceived by the worker, and the corresponding evaluations of others. On the basis of all the above-mentioned studies, the subjective ratings of job incumbents can be regarded as a sufficient and valid indicator of the extent of the job characteristics present in their jobs. This then also validates what Taber, Beehr and Walsh (1985: 32) refer to as the common organizational research strategy of using only selfreport measures of job characteristics, as yielded by the JDS. It is furthermore recommended that the revised JDS (see Appendix A) be used to measure the subjective job characteristics. 


\section{Additional job characteristics}

The supplementary variables, namely feedback from others and dealing with others, are included in the JDS to aid the diagnosis of jobs and the reaction of workers to their jobs (Hackman \& Oldham, 1975: 162). Sims, Szilagyi and Keller (1976) and Evans, Kiggundu and House (1979) as well as Hogan and Martell (1987) have found little evidence to justify adding these two variables to the set of five core job characteristics. Apart from these studies though, research in general has neglected to test the viability of including these two additional variables.

In the absence of valid reasons to the contrary, these two additional job characteristics can therefore not be justifiably added to the standard five job characteristics. They can, however, be utilized by those technologists who may find these indices useful for a specific intervention scenario, and they also serve some utility as a guideline for researchers attempting to expand the nature and scope of the job characteristics.

\section{Motivating Potential Score (MPS)}

The model accentuates the contribution of each of the separate five job characteristics in enhancing motivation, satisfaction and performance. It is nevertheless also informative to combine the five job characteristics into a single index which reflects the overall potential of a job to foster positive personal and work outcomes. Such a multiplicative index (as depicted in the section on the job diagnostic survey) was formulated by Hackman and Oldham (1974) and is known as the MPS. This index provides an indication of the extent of job complexity.

Ferris and Gilmore (1985) point out that the traditional multiplicative index is not the only index used in research. Their study compares the utility of the multiplicative index of Hackman and Oldham $(1974,1975,1976,1980)$, a simple unweighted additive index, and a weighted additive index, when moderator effects are tested. The unweighted additive index of job complexity is computed by adding the scores of the five job characteristics. The weighted additive job complexity index is compiled as follows:

Job complexity $=2$ (Skill variety) + Task identity + Task significance +2 (Autonomy) + Feedback

Data was collected from 94 nursing employees. A moderated regression analysis revealed that the probability of detecting moderator effects is increased when using the traditional multiplicative index compared to utilizing either of the two additive indices.

Evans and Ondrack (1991), in a replication of afore-mentioned study, however, declare their preferred formula to be the unweighted additive index. Four versions of the formula were tested using a sample of 1193 male, blue-collar employees who lived and worked in Ontario, Canada. Using a hierarchical multiple regression analysis, little support was found for the traditional multiplicative index. The most suitable formula was found to be the simple additive version.
These findings also coincide with that of Arnold and House (1980) who state that the multiplicative index of the MPS is unnecessarily complex, and that a simple additive index suffices.

Fried and Ferris (1987), too, compared the multiplicative MPS index with the simple additive index by conducting a metaanalysis of nearly 200 studies. They conclude that the simple additive index of job complexity is a better predictor of work outcomes than the multiplicative index. Even more emphatically, Hinton and Biderman (1995: 355), applying hierarchical regression to a sample of 195 managerial and nonmanagerial positions, state that 'no evidence for the multiplicative formulation of the MPS was found'.

In conclusion, although the algorithm for computing the original MPS is provided by Hackman and Oldham (1974, $1975,1976,1980)$, the rationale for its computation is not stated in the literature. Based on available research results, the simple additive index is recommended for use in job redesign interventions.

\section{Personal and work outcomes}

The Job Characteristics Model originally included internal work motivation, satisfaction with work, quality work performance, and absenteeism and labour turnover as personal and work outcomes (Hackman \& Oldham, 1974, 1975, 1976). In subsequent refinements of the model, quality work performance was reformulated as work effectiveness, and absenteeism and labour turnover was discarded. Satisfaction with work was redefined as general job satisfaction and a new dependent variable, namely growth satisfaction, was introduced (Hackman \& Oldham, 1980: 90). Growth satisfaction had previously been regarded as a moderator variable in the original conceptualization (Hackman \& Oldham, 1975: 162).

Algera (1990: 96) points out that research on the model has focused more on the personal outcomes than on the work outcomes. A possible reason for this is that the measurement of the work outcomes (that is, productivity and performance) is notoriously difficult (Kelly, 1992: 754). O’Brien (1982: 398) also indicates that the model has not been shown capable of predicting individual productivity. Hackman and Oldham (1976: 271) state that the relationships between the job characteristics and both absenteeism and work performance are weaker than the relationships between the job characteristics and the personal outcomes. Kemp and Cook (1983) report that the job characteristics strongly correlate with motivation and satisfaction, but that the job characteristics are less reliably related to measures of turnover, absenteeism and performance. This particular finding is supported by elaborations in the next section where research results pertaining to the relationships between variables in the model will be discussed.

Of specific relevance, however, is the nature of the items used in the original JDS to measure the personal outcomes, that is internal work motivation, general job satisfaction and growth satisfaction. As discussed in the section on the factor 
structure of the job characteristics, studies on the dimensionality of the job characteristics, as measured with the original JDS, propose from a one- to a five-factor solution. This problem was dealt with successfully by Idaszak and Drasgow (1987) by replacing reverse-score items with positively-worded items to measure the job characteristics, thereby obtaining a five-factor solution as proposed by the model. Kulik, Oldham and Langner (1988) indicate the possibility that the personal outcomes are subject to the same impurities as the job characteristics when measured with the original JDS. It is suggested that improvements in the criterion-related validity of the JDS may be observed only when both the job characteristics and personal outcomes measures are all positively worded.

In conclusion, studies on the model tend to favour general job satisfaction, growth satisfaction and internal work motivation as dependent variables. The use of the revised JDS (see Appendix A) to measure these personal outcomes is also recommended.

\section{Review and evaluation: relationships between variables in the Job Characteristics Model}

The Job Characteristics Model sets forth job characteristics as independent variables and personal and work outcomes as dependent variables. The psychological states are mediators of the relationships between job characteristics and outcomes. The employee's growth-need strength, satisfaction with pay, security, supervision and co-workers, as well as the employee's level of knowledge and skill, moderate both the relationships between the job characteristics and the psychological states and the relationships between the psychological states and the personal and work outcomes.

\section{Relationships between job characteristics and outcomes}

Researchers like Turner and Lawrence (1965), Brief and Aldag (1975), Oldham, Hackman and Pearce (1976), Hackman, Pearce and Wolfe (1978), Wall, Clegg and Jackson (1978), Oldham and Brass (1979), Hackman and Oldham (1980), Roberts and Glick (1981), Caldwell and O'Reilly (1982), Hunt, Head and Sorensen (1982), Terborg and Davis (1982), Algera (1983), Lee, McCabe and Graham (1983), Orpen (1983), Loher, Noe, Moeller and Fitzgerald (1985), Ondrack and Evans (1986), Fried and Ferris (1987), Gerhart (1987), Champoux (1991), Spector and Jex (1991), Boonzaier and Boonzaier (1994) and Renn and Vandenberg (1995) conclude that job characteristics influence outcomes. Furthermore, Adler, Skov and Salvemini (1985), as well as James and Tetrick (1986) and Mathieu, Hofmann and Farr (1993), propose a reciprocal relationship between job characteristics and outcomes.

The South African study of Boonzaier and Boonzaier (1994) warrants attention at this juncture. A sample of 4012 employees of a community service organization stationed at 46 organizational units was drawn to test the validity of the model. Results show that MPS is strongly associated with general job satisfaction $(\mathrm{r}=0,48)$, employee growth opportunities at work $(\mathrm{r}=0,58)$ and employee internal motivation $(\mathrm{r}=0,41)$. These findings coincide with the metaanalyses of Loher, et al. (1985), Spector (1985) and Fried and Ferris (1987).

Lee, et al. (1983) provide evidence for the generalizability of the relationships between job characteristics and outcomes to employees working within the public sector. Government workers were thus found to react similarly to workers within the private sector with regards to the presence of the job characteristics.

A positive relationship between job characteristics and personal outcomes was found specifically for retail salespeople in studies by Teas $(1981,1982)$ and Dubinsky and Skinner (1984). The study of Becherer, Morgan and Richard (1982), of industrial sales personnel, also shows highly significant correlations between job characteristics on the one hand, and internal motivation, general satisfaction and growth satisfaction on the other.

Stone (1986) reviewed empirical evidence relating to the relationships described in the model and found that job complexity correlated strongly with general job satisfaction, both in the field $(\mathrm{r}=0,63)$ and the laboratory $(\mathrm{r}=0,53)$. Loher, et al. (1985), however, found a weaker correlation $(\mathrm{r}=0,39)$ in their sample of mainly laboratory studies. Stone (1986) found contradictory results in that job complexity was positively correlated with job performance $(\mathrm{r}=0,30)$ in 11 field studies, but showed a negative correlation $(\mathrm{r}=-0,26)$ in three laboratory studies.

All the above findings have specific implications for managers of human resources. Worker motivation and satisfaction can be enhanced by increasing the extent of the five job characteristics present in a job. This is accomplished by implementing the job redesign strategies reported by Boonzaier and Boonzaier (1994).

It is important at this juncture to take cognisance of Algera's (1990: 97-98) conclusion that strong relationships exist between the perceived job characteristics and personal outcomes, but that the correlations between the job characteristics and work outcomes are much weaker. The meta-analysis of Fried and Ferris (1987) also makes a clear distinction between the strength and consistency of the relationships between the five job characteristics and the personal outcomes on the one hand, and the five job characteristics and the work outcomes on the other. Their results indicate that feedback has the strongest relationship with general job satisfaction $(90 \%$ credibility value 0,43$)$, that autonomy has the strongest relationship with growth satisfaction $(90 \%$ credibility value 0,71$)$ and that skill variety has the strongest relationship with internal work motivation $(90 \%$ credibility value 0,52$)$. On the other hand, the relationships between the job characteristics and job performance are weak $(90 \%$ credibility value: ranging from 0 to 0,13$)$. The relationships between the job characteristics and absenteeism are also weak $(90 \%$ credibility value: ranging from $-0,29$ to 0,04$)$. The relationships between job characteristics and personal outcomes are thus generally stronger and more consistent than the relationships between 
job characteristics and work outcomes.

In conclusion, it can be said that a major strength of the Job Characteristics Model lies in the empirical support for the positive relationships between the job characteristics and personal outcomes. However, when comparing the relationships between the job characteristics and personal outcomes on the one hand, and the relationships between the job characteristics and work outcomes on the other, the model itself is disconfirmed due to the discrepancy in causal patterns between the job characteristics and personal versus work outcomes. Job redesign practitioners should focus on the model's positive feature, that is, the strong superior relationships between the job characteristics and personal outcomes, and the practical implications thereof.

\section{Moderators and mediators of the relationships between job characteristics and outcomes}

Worker characteristics (psychological states, growth-need strength and knowledge and skill) and work environment characteristics (satisfaction with pay, security, supervision and co-workers) are specified as moderators and mediators of the relationships between the independent and dependent variables of the model (refer to Figure 1).

\section{Worker characteristics}

The Job Characteristics Model depicts certain worker characteristics in order to explain an intervening or moderating influence on the relationships between job characteristics and outcomes. Worker characteristics include three psychological states (experienced meaningfulness, experienced responsibility, and knowledge of results) which are regarded as mediators of the relationships between the job characteristics and outcomes (Hackman \& Oldham, 1980; Johns, Xie \& Fang, 1992: 659). Two further worker characteristics are growth-need strength, and knowledge and skill (Kulik, Oldham \& Hackman, 1987: 283) which are depicted in the model as moderators both between the job characteristics and psychological states, and between the psychological states and outcomes, although Johns, Xie and Fang (1992: 659) report that most researchers have restricted moderator tests to the direct relationships between the job characteristics and outcomes.

It is important at this juncture to take note that employee knowledge and skill, as specified by the model, 'has never been tested directly' (Johns, Xie \& Fang, 1992: 659). Furthermore, a contradiction exists in the literature as Hackman and Oldham (1980: 90) include knowledge and skill as a moderator variable, but Kulik, Oldham and Hackman (1987: 286) report that 'it is still unknown whether employee knowledge and skill will determine how employees will respond to a job's motivating potential'. No empirical support for the knowledge and skill variable within the context of the model has been located and therefore no further discussion of this variable is warranted.

Empirical studies with regards to the role of the psychological states and growth-need strength in the model will now be discussed.

\section{Psychological states}

The Job Characteristics Model 'posits that all three of the psychological states must be experienced by an individual if desirable outcomes are to emerge' (Kulik, Oldham \& Hackman, 1987: 280). However, the intervening or mediating influence of the psychological states on the relationships between job characteristics and outcomes has been questioned (Hackman \& Oldham, 1976; Wall, Clegg \& Jackson, 1978; Renn \& Vandenberg, 1995).

As contained in the theoretical statements of the Job Characteristics Model (refer to the section on the implications of the model), of relevance at this juncture is

- whether all three psychological states are necessary for positive outcomes to emerge;

- whether the relationships between the job characteristics and psychological states exist as specifically prescribed by the model; and

- $\quad$ whether the psychological states are complete mediators of the relationships between the job characteristics and outcomes.

Hackman and Oldham (1976: 262-264), in their original formulation of the model, in actual fact provide evidence of a difference in status between the psychological states. They tested the hypothesis whether predicting the outcomes (internal work motivation, general job satisfaction, growth satisfaction, absenteeism and rated work effectiveness), using the psychological states, is maximized when the three psychological states are used as a single unit, versus when any of the possible pairs of the psychological states are used, or when the psychological states are utilized individually. Regressions were computed predicting the outcome measures on the basis of, firstly, all three psychological states as a unit, secondly, the three possible pairs of psychological states, and thirdly, each of the three psychological states singularly. Results indicate that any single psychological state significantly predicts the outcomes, and that a significant increase in predictive value (that is, an increase in R-squared) is only achieved by the further inclusion of any possible pair of states. The strongest predictive combination is thus any two of the three psychological states. Arnold and House (1980) also found little support for the hypothesis that all three psychological states are necessary for the development of specifically internal work motivation. Fried and Ferris (1987) favour reducing the number of psychological states from three to two, by integrating experienced meaningfulness and experienced responsibility into a single dimension. Their results also fail to support the intervening effect of the psychological states on especially the job characteristics/work performance relationships. Renn and Vandenberg (1995) collected data from 188 subjects performing a range of different jobs which showed that not all three psychological states are necessary to maximize the explanation of outcome variance. This finding coincides with the finding of Johns, Xie and Fang (1992). 
The relationships which do exist between the job characteristics and the psychological states do also not coincide fully with those specified by the model. The study of Becherer, Morgan and Richard (1982), while validating some of the relationships between the job characteristics and the psychological states, also confutes others. While the regression equation for the knowledge-of-results variable employs standardized regression weights as predicted by the model (that is, feedback predicts knowledge of results), the regression equations for the other two psychological states show mixed results. According to the model, only autonomy should be related to experienced responsibility. However, the standardized regression coefficients for the other job characteristics (that is, skill variety, task identity, task significance, and feedback) are as large as or larger than that for autonomy. Also autonomy and feedback contribute, together with the posited relationships, to predicting variance in the experienced-meaningfulness-of-work variable.

Renn (1989) tested the model in a longitudinal research design utilizing structural equation methodology by drawing a sample of 90 employees representing seven different job categories in an insurance company. Autonomy predicted experienced responsibility, and feedback predicted knowledge of results. Skill variety, task identity and task significance, however, did not predict experienced meaningfulness. This study thus, too, only partially validates the specified relationships between the job characteristics and the psychological states.

The meta-analysis of Fried and Ferris (1987: 303) shows that skill variety has the strongest relationship with experienced meaningfulness $(90 \%$ credibility value 0,71$)$ and that task significance also has the strongest relationship with experienced meaningfulness $(90 \%$ credibility value 0,62$)$, thus supporting the theory with regards to the relationships between these two job characteristics and the corresponding psychological state. Task identity, however, showed the strongest relationship with experienced responsibility $(90 \%$ credibility value 0,40 ), while autonomy showed a similar strength of relationship with experienced meaningfulness and experienced responsibility $(90 \%$ credibility value 0,61$)$ and job feedback related similarly to all three psychological states, thus not supporting the theoretical statements regarding the specified relationships between the job characteristics and the psychological states.

With regards to the issue of the psychological states posing as complete mediators in the model, the study of Renn and Vandenberg (1995), using regression procedures, shows that the psychological states are only partial mediators of the relationships between the job characteristics and outcomes, thus contradicting the theoretical statement of the model implicating complete mediation. The results do, however, indicate that the psychological states explain significant amounts of outcome variance beyond the job characteristics.

Testing an alternative model, by excluding the psychological states, Wall, et al. (1978) showed that the alternative model accounts for a significantly greater portion of variance than does the Job Characteristics Model. The alternative model showed a direct causal relationship between job characteristics and work behaviour. The studies of Fried and Ferris (1987) and of Hogan and Martell (1987) also show that the psychological states do not increase the explanatory power of the model. Questions have thus been posed regarding the mediating role of the psychological states. Fried and Ferris (1987) state, in their review and meta-analysis of the validity of the Job Characteristics Model, that only a few studies have focused on this issue of psychological states as mediator variables. Research has, however, started focusing on other possible mediators (for example, attention state) of the relationships between job characteristics and outcomes (Fox \& Feldman, 1988).

Roberts and Glick (1981: 197-198) refer sceptically, in their evaluation of the literature, to the value and role of the psychological states in the Job Characteristics Model: 'A psychological state construct was apparently introduced as an intervening variable to increase the explanatory power of the model'. Wall and Martin (1987: 68) ask for the exclusion of the psychological states from the model: 'It appears that the critical psychological states are an unnecessary elaboration which concern for parsimony would lead one to exclude'.

Johns, Xie and Fang (1992) confirm the role of the psychological states as mediators, but support the notion of a single-factor model for the psychological states as espoused by Hogan and Martell (1987). Concern is also voiced by the former researchers with regards to the method variance problem when measuring the psychological states using the JDS, suggesting that it might be wise to avoid measuring both job characteristics and psychological states with the same instrument (Johns, Xie \& Fang, 1992: 672).

The model presents the critical psychological states as the 'causal core of the model' (Hackman \& Oldham, 1976: 255). Wall, Clegg and Jackson (1978: 255) argue, however, that amidst the suspect equal status of the psychological states in the model, the strong relationships between the job characteristics and outcomes nonetheless ensure the same implications for job redesign practices, thus rendering the use of the psychological states construct useless in practical terms. O'Brien (1982: 386), furthermore, states that the job characteristics and psychological states items in the JDS measure basically the same concepts.

With regards to the role of the psychological states in the model, Wall and Martin (1987: 68) state that 'examination of this part of the model has confirmed neither the predicted differential pattern of relationships between the five job characteristics and the three psychological states, nor that these intervening variables are required to account for the relationship between the core job dimensions on the one hand and the outcome variables on the other'. Champoux (1991: 432) seconds this pronouncement with the conclusion that 'research results to date with the critical psychological states do not give unequivocal support to this part of the theory'.

In conclusion, the specified relationships between the job characteristics and psychological states are not consistently confirmed by empirical research, as some job characteristics relate to the psychological states in ways not stated by the 
model. The status of the three states also differ, with experienced meaningfulness playing a prominent role, knowledge of results an insignificant role, and experienced responsibility contributing intermediate predictive utility. The psychological states do explain, however, significant amounts of outcome variance beyond the job characteristics, but are regarded as being of no practical use, given the practical utility of the job characteristics and the personal outcomes as contained in the JDS. Furthermore, the psychological states cannot be regarded as complete mediators of the relationships between the job characteristics and outcomes as specified in the theoretical statements of the model. The inclusion of the psychological states also increases the likelihood of method variance. Above-mentioned studies thus, in general, fail to support the mediating effect of the psychological states on the job characteristics/outcomes relationships as specified by the model.

\section{(b)}

\section{Growth-need strength (GNS)}

The concept of growth-need strength is based on the work of Maslow $(1943,1954)$. The Job Characteristics Model refers to the higher-order needs of the worker as growth-need strength. GNS is viewed as one of the moderator variables because it is depicted as influencing the relationships between job characteristics and psychological states as well as the relationships between the psychological states and personal and work outcomes. Growth-need strength represents the need for personal growth and development within the job environment. Individuals with a strong growth-need will desire that a high degree of the job characteristics be present in their jobs and will constantly seek opportunities for growth within the job environment. When jobs possess a high degree of the job characteristics, and workers deliver quality work performance, the higher-order needs are satisfied and workers experience a positive internal feeling, namely the three psychological states. Individuals experience a reward for their performance in the form of higher-order need satisfaction, as well as a positive internal feeling, and are thus further motivated to sustain their good performance. The higher-order needs can therefore be satisfied on a continual basis without detracting from the strength of the drive for further need satisfaction (Hackman \& Lawler, 1971: 262).

In the literature, however, the influence of growth-need strength as a moderator variable in the model is questioned. Umstot, Bell and Mitchell (1976), Orpen (1979) and Graen, Novak and Sommerkamp (1982) found that GNS did not moderate correlations between job characteristics and job performance, while Wall and Clegg (1981) found that GNS did not moderate correlations between job characteristics and intrinsic motivation. Maillet (1984) suggests, based on a sample of 117 Canadian penitentiary guards, that the moderator effects of GNS are, at best, minimal with respect to the relationships between MPS and work outcomes. Hunt, Head and Sorensen (1982) also show that GNS displays an insignificant moderating influence on the relationships between job characteristics and personal outcomes for pharmacists employed in a private hospital. The study of Johns, Xie and Fang (1992), too, found very little evidence for the moderating role of GNS. O'Brien (1982: 393), in an evaluation of various studies, reports on the state of research regarding growth-need strength as follows: 'The evidence for moderator effects of growth needs is weak'. Roberts and Glick (1981) arrived at the same conclusion.

The strongest empirical evidence is provided by three metaanalyses of the moderating effects of GNS on the relationships between job characteristics and various outcome variables. The studies reviewed in these meta-analyses (Fried \& Ferris, 1987; Loher, et al., 1985; Spector, 1985) present inconsistent conclusions re the moderating influence of GNS.

Forshaw (1985: 97), in a South African study of the moderating influence of growth-need strength on the relationships between job characteristics, psychological states, and personal and work outcomes, found only partial support for GNS. Champoux (1991), in testing the model utilizing 247 state agency employees, also states that the moderating influence of GNS is not as widespread as the theory implies. Graen, Scandura and Graen (1986) reviewed 26 studies and also found the results inconclusive. It would appear as if the individual's need to grow cannot be accepted per se as an explanation for motivated work behaviour within an enriched job environment. Wall and Martin (1987: 71) concur that research relating to GNS is inconsistent and does not present a coherent pattern of findings.

Roberts and Glick (1981: 196) introduce a further shortcoming by stating that although the model specifies desirable job characteristics for workers with high GNS, it makes no attempt to identify desirable job characteristics for low GNS individuals. The model also provides no indication of the motives of, and therefore the job characteristics that could appeal to, the low GNS worker (Britt \& Teevan, 1989).

Jackson, Paul and Wall (1981) ascribe the inconclusive findings relating to GNS as a moderator to deficient empirical work by researchers. They argue that studies examining the moderator effect of GNS have usually utilized the JDS to measure GNS and have taken measures of all the relevant variables on the same occasion. Respondents thus strive for consistency within the confines of the JDS. Having, for example, stated that a specific job characteristic is valued (indicating a high GNS), and that this characteristic is present in the job, little option exists but to report job satisfaction. The measures of GNS are also closely related to the measures of the job characteristics, thus drawing attention to this relationship and thereby the need for consistent responses. They also cite the use of discrepant analytical procedures as a shortcoming in GNS research. Findings regarding GNS as a moderator in the model may thus be method-bound.

Pokorney, Gilmore and Beehr (1980) focused on the different statistical techniques employed to test for moderator effects as a possible reason for inconclusive findings. When comparing the correlation and regression results of the same data set, the correlation subgroup analysis lends more support to the hypothesized moderating effect of GNS than does the result of the regression analysis. A lack of methodological refinements may thus also contribute to the inconclusive results regarding the moderating role of GNS in the model. Vecchio (1980: 
480) has two criticisms of the published research on individual difference moderators. The first relates to the nature of the moderator variables studied: the variables are predominantly personality variables and the scales used to measure this type of variable are regarded as poor predictors. The second criticism relates to the nature of the sample: a restricted focus has been maintained in the sampling procedure where the samples, in general, could be regarded as relatively homogeneous.

Graen, Scandura and Graen (1986: 485) provide adequate reason why the conceptualization of GNS as a moderator variable in the model is based upon a faulty premise. They explain that GNS refers to the extent of employee motivation for growth on the job, that is an employee's desire for the challenge of new learning. Growth-need strength thus assesses individual needs for growth opportunities with individuals responding to particular growth opportunities based on their GNS. But the MPS represents only the current level of job characteristics present in the job; nowhere does the JDS measure opportunities for growth in the job per se. It is thus only actual changes in job characteristics that hold prospects for growth and bring GNS as a relevant variable into play. As moderator studies have focused only on the current level of job characteristics present in a job, the influence of GNS as a moderator variable in the model has not been adequately addressed.

It is important to note at this juncture that Hackman and Oldham (1975: 163), in their original conceptualization, refer to GNS as a 'malleable individual difference characteristic' constructed to be a reliable indicator of individual needs. In a further discussion, Hackman and Oldham (1976: 259) use such terms as 'the possibility', 'It may be' and 'tentatively' when referring to the role of GNS as a moderator in the model. Their 'present findings provide no reason to expect that the ultimate impact of working on enriched jobs will be more negative than positive for any group of employees, regardless of the level of growth-need strength' (ibid.: 275), thus actually claiming GNS not to be a moderator in the model. In a study by Kulik, Oldham and Hackman (1987: 294), concern is voiced regarding the measurement strategy employed by the JDS to assess the growth-need strength of employees, thus reflecting on the suspect validity of the GNS construct. Roberts and Glick (1981) indicate, based on low intercorrelations, that the two original formats of the GNS scales measure different constructs. They furthermore question the reliability and validity of these two GNS constructs.

The conceptualization of GNS is based on the need hierarchy of Maslow (1943, 1954). Thierry and Koopman-Iwema (1984: 138), however, find very little empirical support for Maslow's theory. They reason that each category of needs is complex in composition and thus complicates the operationalization of partial needs. Another criticism concerns the assumption of prepotency in the hierarchy structure which postulates that the 'next' need will not motivate behaviour until the 'previous' one has been satisfied. The same authors report that research shows that behaviour is aimed at satisfying various categories of needs simultaneously and that this precondition is not valid. Furthermore, the specific categories of needs are questioned and remain suspect. Wahba and Bridwell (1983: 34) also report that although Maslow's theory is widely accepted, little research evidence exists to support it.

In conclusion, it can be stated that the nature and manifestation of growth-needs, the measurement thereof, as well as how need satisfaction actually occurs, remain polemical. Problems therefore exist in accepting growth-need strength as a measure of worker characteristics within the work situation. Above-mentioned evidence seriously questions the role of GNS as a moderator of the relationships between job characteristics and psychological states, as well as of the relationships between psychological states and outcomes.

\section{Work environment characteristics}

The Job Characteristics Model states that jobs which possess a high motivational value (that is, a high degree of the job characteristics) will give rise to positive psychological states, which will in turn influence work behaviour positively, specifically for workers who are satisfied with pay, security, co-workers and supervisors. If workers waste unnecessary energy on frustrating job environment factors, the strength of the relationships between job characteristics and work behaviour is negatively influenced (Oldham, 1976; Oldham, Hackman \& Pearce, 1976; Hackman \& Oldham, 1980). Oldham, et al. (1976: 401) sought to illustrate that the work context variables and GNS, individually and in combinations, moderate the relationships between job characteristics and outcome measures. Their research design and attendant analysis of data, however, did not include all the possible combinations of the work context and GNS variables to warrant the acceptance of such a postulation. Katz (1978: 705) and Brousseau (1983: 34) agree that the influence of the broader work situation, or work environment characteristics, should be included in job redesign interventions. Although Johns, Xie and Fang (1992) also found some support for this notion, they conclude that 'the results provide relatively good support for the basic (unmoderated) job characteristics model' (ibid:: 674).

The study of Hunt, Head and Sorensen (1982) also shows that satisfaction with pay, security, co-workers and supervisors displays an insignificant moderating influence on the relationships between job characteristics and outcomes for pharmacists employed in a private hospital. Various other studies also show insignificant moderator effects for the context variables in the model (Abdel-Halim, 1979; Katerberg, Hom \& Hulin, 1979; Champoux, 1981; Ferris \& Gilmore, 1984).

Champoux and Howard (1989) found complex interactions between the characteristics of jobs and work context variables for medical technologists. Champoux (1992) continued this line of research and specifically defined several different forms of interaction between the complexity of a job and the work context in determining work behaviour. Instead of the context factors, for example, distracting employees from experiencing the characteristics of their jobs as specified by the model, research has shown that incumbents working 
within negative contexts may 'escape' from such environments and rather turn to the intrinsic nature of their jobs for gratification. Job redesign programmes should therefore begin with a systematic diagnosis of the current state of jobs, workers and the work context.

Kulik, Oldham and Hackman (1987: 285) claim that 'employees who have high needs for growth, who possess adequate knowledge and skills, and who are satisfied with the work context, will be best "fit" (ic) to high MPS jobs', signifying that the moderators do not operate in isolation from one another, but rather jointly, in combination with each other. This implies that the testing of any of these moderators individually, or in any combination other than specified, is not in accordance with the conceptualization of the relationships as specified by the model. The concept of joint moderators, as depicted in the model, is also espoused by Kemp and Cook (1983).

Apart from the job environment characteristics specified by the Job Characteristics Model, researchers have also considered other job environment factors as moderator variables in the model. To this end, such characteristics as functional speciality (Dunham, 1977), work involvement (Katerberg, Hom \& Hulin, 1979), organizational structure (Vecchio \& Keon, 1981), quality of the social environment at work (Repetti \& Cosmas, 1991), type of industry (Yeh, 1996) and many other variables (Griffeth, 1985: 74) have been evaluated.

Griffeth (1985: 75) comments on the results of studies which focus on the moderating role of job environment characteristics on the relationships between job characteristics and work behaviour: 'However, inconsistent findings have also been reported among these studies'. Wall and Martin (1987: 74) summarise as follows: 'The literature relating work design to organizational context is at present fragmented. It suggests a range of factors it is plausable to take into account, but as yet there is insufficient empirical evidence to identify the most salient among these'.

In conclusion, the inclusion of work environment characteristics as moderator variables in the Job Characteristics Model confuses the relationships in the model. The role of work environment characteristics as moderators of the relationships between job characteristics and psychological states, as well as of the relationships between psychological states and personal and work outcomes, is seriously questioned.

A major weakness of the Job Characteristics Model is its inadequate attempt to stipulate specific worker characteristics which influence, mediate or moderate the relationships between job characteristics and work behaviour. A further shortcoming of the model is the weak empirical support for the work environment characteristics as moderator variables of the specified relationships between the independent and dependent variables. Ganster (1980: 145) refers to these conclusions derived from empirical evidence as the 'continual failure to document reliable moderator effects'. Algera (1984: 189) provides an appropriate summation of the state of research on the influence of worker characteristics and work environment characteristics on the relationships between job characteristics and work behaviour: 'To sum up, let us state that the job characteristics model does offer pointers for diagnosing work situations, but from a theoretical perspective the model is still fairly obscure. This is particularly true for the critical psychological states and the role of moderator variables'.

\section{Conclusion and recommendations for future research}

Porter and Miles (cited in Steers \& Porter, 1991: 20-24) stipulate specific criteria for dealing comprehensively with phenomenon in the workplace relating to demotivation, dissatisfaction and marginal performance. According to these criteria, three dominant sets of variables constitute the world of work, namely characteristics of the job, characteristics of the worker and characteristics of the work environment.

The modern behavioural science approach to job redesign, in producing the Job Characteristics Model and the attendant JDS, has focussed with different degrees of rigour and success on the criteria laid down by Porter and Miles (ibid.). The research evidence presented in this review confirms strong positive relationships between the job characteristics as independent variables and motivation and satisfaction as dependent variables. Internal work motivation, general job satisfaction and growth satisfaction serve as valid dependent variables. The five job characteristics, namely skill variety, task identity, task significance, autonomy, and feedback are verified as valid independent variables. However, original formulations of the model are shown to specify inappropriate and inadequate worker and work environment characteristics as moderators/mediators of the relationships between the independent and dependent variables.

The strong positive relationships between job characteristics and work motivation and satisfaction impacts on the role and functions of managers and human resource practitioners since motivation and satisfaction in the workplace can be increased by enhancing the extent of the five job characteristics present in a job. Efforts to enrich the jobs in organizations thus lead to desirable motivation and satisfaction increases and associated organizational performance improvements. Job enrichment as a technology should therefore be implemented in organizations to enhance desirable work behaviours. The Job Characteristics Model, its attendant JDS and norms, the set of action steps and implementing concepts (Boonzaier \& Boonzaier, 1994) serve collectively as a technology for job enrichment.

The review furthermore suggests that worker and work environment characteristics influence the dependent variables in important ways, but that no single characteristic explains a significant amount of outcome variance. More specifically, worker characteristics, in particular the psychological states and GNS, remain inadequately explored and polemical. This is possibly due to the fact that job redesign research in general and studies pertaining to the Job Characteristics Model in particular, assume that situational factors are largely 
responsible for the behaviour of employees (Arvey, Carter \& Buerkley, 1991: 364). Staw and Ross (1985: 469) note that work behaviour is rarely formulated as having an endogenous source of variance, that is to say, a source which is reflective of the state of the person. When person variables are used, they are used only to specify the type of person for whom certain situational or environmental variables are predictive. Hackman and Oldham (1974, 1975, 1976, 1980) exhibit this conceptualization by focusing on person characteristics within a specific situation, condition or environment. In the Job Characteristics Model, worker characteristics, like the psychological states and GNS, are conceptually defined in terms of the characteristics of a worker for whom job characteristics provide need satisfaction. Endogenous causes of work behaviour are thus formulated in terms of exogenous factors, and the influence of comprehensive endogenous or person factors is ultimately disregarded.

The evidence reviewed implicates the model as flawed not only with regards to worker characteristics, but also with regards to work environment characteristics as moderator variables. Scrutiny of the work environment characteristics in the Job Characteristics Model leads to the conclusion that a smorgasbord of convenient variables have been considered and indiscriminately included.

To facilitate theory development, it is recommended that the following research suggestions and methodological issues be explored and clarified:

- $\quad$ The basic unmoderated/unmediated Job Characteristics Model (with job characteristics as independent variables and personal outcomes as dependent variables) can be utilized as a point of departure in future model developments. The attendant revised JDS (Appendix A) can serve as the measuring instrument of aforementioned variables.

- $\quad$ Further worker and work environment variables need to be identified, defined and examined as possible mediators and moderators of the relationships between the job characteristics and outcomes. These variables should be chosen on a sound theoretical basis. Efforts should also include the re-examination and modification of current Job Characteristic Model variables, for example psychological states, GNS and work environment characteristics. Relationships between personality and motivation could also be established. Current research relating to the effect of a five factor model of personality (Morrison, 1996), positive affect (Munz, Huelsman, Konold \& McKinney, 1996), negative affectivity (Hochwarter, Zellars, Perrewé \& Harrison, 1999) and dispositional affect (Wright \& Staw, 1999) on job characteristics and work motivation and satisfaction serve as examples of such developments.

- Interrelationships between the variables of the Job Characteristics Model were only tested at one specific point in time. This does not grant the opportunity for the dynamic influence of a change in any one or more of the job characteristics, for example, to manifest over time in the worker's experienced satisfaction with her/his job. By assessing the different variables and relationships between variables of the model over an extended period of time, researchers may learn more about causal patterns amongst the variables. Griffin (1991) did, however, make a contribution to addressing this gap in the research literature by examining the effects of job changes on specified outcomes over intervals of 6, 24 and 48 months. Wright and Staw (1999) also conducted two longitudinal field studies, the first over four time periods and the second over two time periods. These latter studies focused on the relationships between measures of affect and supervisory performance ratings. Barring these afore-mentioned studies though, further longitudinal and experimental research should be conducted relating to Job Characteristics Model development. Investigations of the interactions, over time, between person and situation characteristics and their relationship to work outcomes are important for future research endeavours.

- Research should be guided by specific theoretical statements and taxonomies grounded on sound theory and empirical studies.

- Further clarification is needed with regards to the interaction between variables in the model. Reciprocal influences between variables may exist as pointed out by Adler, Skov and Salvemini (1985), James and Tetrick (1986) and Mathieu, Hofmann and Farr (1993).

To improve practical job enrichment interventions, the following guidelines are provided for the future use of the model and the accompanying JDS:

- The personal outcomes, namely general job satisfaction, growth satisfaction and internal work motivation, should be retained as dependent variables.

- In the absence of reliable performance data, work outcomes should not be considered.

- The use of the five-factor structure of the job characteristics, as proposed by Hackman and Oldham (1980), is recommended.

- The revised version of the original JDS, using only positively worded items (Appendix A), is suggested for use by job redesign practitioners seeking to measure the five subjective job characteristics and the three personal outcomes.

- In the absence of valid reasons to the contrary, the two additional job characteristics (namely feedback from others and dealing with others) should be excluded from a diagnostic procedure.

- The simple additive index for computing the Motivating Potential Score is recommended. 
- $\quad$ The worker characteristics (psychological states, growthneed strength, and knowledge and skill) proposed by the model should be excluded from job enrichment interventions, pending the revision of current and the development of additional worker characteristics.

- The work environment characteristics (satisfaction with pay, security, co-workers and supervision), on the basis of a paucity of research support for their moderating role, should be viewed with circumspection within the confines of the model, but included in job redesign efforts due to their diagnostic value.

One of the central future research goals relating to the Job Characteristics Model should be the identification, definition and measurement of appropriate worker and work environment characteristics (person and environment factors) which would account for significant amounts of variance in motivation and satisfaction beyond the influence of the job characteristics and so enhance the predictive validity and practical usefulness of the model.

\section{References}

Abdel-Halim, A.A. 1979. 'Individual and interpersonal moderators of employee reactions to job characteristics: A reexamination,' Personnel Psychology, 32: 121-137.

Adler, S., Skov, R.B. \& Salvemini, N.J. 1985. 'Job characteristics and job satisfaction: When cause becomes consequence,' Organizational Behavior and Human Decision Processes, 35: 266-278.

Algera, J.A. 1983. 'Objective and perceived task characteristics as a determinant of reactions by task performers,' Journal of Occupational Psychology, 56:95107.

Algera, J.A. 1984. Task characteristics. In Drenth, P.J.D., Thierry, H.K., Willems, P.J. \& de Wolff, C.J. (Eds.) Handbook of work and organizational psychology. John Wiley.

Algera, J.A. 1990. The job characteristics model of work motivation revisited. In Kleinbeck, H., Quast, H., Thierry, H. \& Häcker, H. (Eds.) Work Motivation. London: Lawrence Erlbaum.

Anthony, W.P., Perrewé, P.L. \& Kacmar, K.M. 1999. Human resource management. Third Edition. Florida: Dryden Press.

Armstrong, M. 1996. A handbook of personnel management practice. Sixth Edition. London: Kogan Page.

Arnold, H.G. \& House, R.J. 1980. 'Methodological and substantive extensions to the job characteristics model of motivation,' Organizational Behavior and Human Performance, 25: 161-183.

Arvey, R.D., Carter, G.W. \& Buerkley, D.K. 1991. 'Job satisfaction: dispositional and situational influences. In Cooper, C.L. \& Robertson, I.T. (Eds.) International Review of Industrial and Organizational Psychology, 6: 359-383.

Becherer, R.C., Morgan, F.W. \& Richard, L.M. 1982. 'The job characteristics of industrial salespersons: Relationship to motivation and satisfaction,' Journal of Marketing, 46:125-135

Birnbaum, P.H., Farh, J. \& Wong, G.Y.Y 1986. 'The job characteristics model in Hong Kong,' Journal of Applied Psychology, 71(4): 598-605.

Boonzaier, B. \& Boonzaier, M. 1994. 'The job diagnostic survey: A functional tool for South African managers,' South African Journal of Business Management, 25(3): 101-109.

Brief, A.P. \& Aldag, R.J. 1975. 'Employee reactions to job characteristics: A constructive replication,' Journal of Applied Psychology, 60: 182-186.

Britt, M.A. \& Teevan, R.C. 1989. 'The relationship of fear of failure to growth need strength and the job characteristics model,' Psychological Reports, 64: 899. 905 .

Brousseau, K.R. 1983. 'Toward a dynamic model of jobperson relationships: Findings, research questions, and implications for work system design,' Academy of Management Review, 8(1): 33-45.

Burke, B.G. 1999. 'Item reversals and response validity in the job diagnostic survey,' Psychological Reports, 85: 213 219

Caldwell, D.F. \& O'Reilly, C.A. 1982. 'Task perceptions and job satisfaction: A question of causality,' Journal of Applied Psychology, 67(3): 361-369.

Cellar, D.F., Kernan, M.C. \& Barrett, G.V. 1985. 'Conventional wisdom and ratings of job characteristics: Can observers be objective?' Journal of Management, 11(3):131-138.

Champoux, J.E. 1981. 'The moderating effect of work context satisfactions on the curvilinear relationship between job scope and affective response', Human Relations, 34: 503-515.

Champoux, J.E. 1991. 'A multivariate test of the job characteristics theory of work motivation,' Journal of Organizational Behavior, 12: 431-446.

Champoux, J.E. 1992. 'A multivariate analysis of curvilinear relationships among job scope, work context satisfactions and affective outcomes,'Human Relations, 45(1): 87109

Champoux, J.E. \& Howard, P.D. 1989. 'Job design and 
work context reactions among medical technologists,' Journal of Applied Health, 18: 177-187.

Cordery, J.L. \& Sevastos, P.P. 1993. 'Responses to the original and revised job diagnostic survey: Is education a factor in responses to negatively worded items?' Journal of Applied Psychology, 78(1): 141-143.

Dubinsky, A.J. \& Skinner, S.J. 1984. 'Impact of job characteristics on retail salespeople's reaction to their jobs, Journal of Retailing,' 60(2): 35-57.

Dunham, R.B. 1976. 'The measurement and dimensionality of job characteristics,' Journal of Applied Psychology, 61(4): 404-409.

Dunham, R.B. 1977. 'Relationship of perceived job design characteristics to job ability requirements and job value,' Journal of Applied Psychology, 62: 760-763.

Dunham, R.B., Aldag, R.I. \& Brief, A.P. 1977. 'Dimensionality of task design as measured by the job diagnostic survey,' Academy of Management Journal, 20: 209-223.

Evans, M.G., Kiggundu, M.N. \& House, R.J. 1979. 'A partial test and extension of the job characteristics model of motivation,' Organizational Behavior and Human Performance, 24: 354-381.

Evans, M.G. \& Ondrack, D.A. 1991. 'The motivational potential of jobs: Is a multiplicative mode necessary?' Psychological Reports, 69: 659-672.

Ferris, G.R. \& Gilmore, D.C. 1984. 'The moderating role of work context in job design research: A test of competing models,' Academy of Management Journal, 27: $885-892$

Ferris, G.R. \& Gilmore, D.C. 1985. 'A methodological note on job complexity indexes,' Journal of Applied Psychology, 70: 225-227.

Forshaw, K.L. 1985. Growth needs strength as a moderator variable in job design. Masters thesis. Cape Town: University of Cape Town.

Fox, S. \& Feldman, G. 1988. 'Attention state and critical psychological states as mediators between job dimensions and job outcomes,' Human Relations, 41(3): 229-245.

Fried, Y. \& Ferris, G.R. 1986. 'The dimensionality of job characteristics: Some neglected issues,' Journal of Applied Psychology, 71(3): 419-426.

Fried, Y. \& Ferris, G.R. 1987. 'The validity of the job characteristics model: A review and meta-analysis,' Personnel Psychology, 40: 287-322.

Ganster, D.C. 1980. 'Individual differences and task design: A laboratory experiment,' Organizational Behavior and
Human Performance, 26: 131-148.

Gerhart, B. 1987. 'How important are dispositional factors as determinants of job satisfaction? Implications for job design and other personnel programs,' Journal of Applied Psychology, 72(3): 366-373.

Graen, G., Novak, M.A. \& Sommerkamp, P. 1982. 'The effects of leader-member exchange and job design on productivity and satisfaction: Testing a dual attachment model', Organizational Behavior and Human Performance, 30: 109-131.

Graen, G.B., Scandura, T.A. \& Graen, M.R. 1986. 'A field experimental test of the moderating effects of growth need strength on productivity,' Journal of Applied Psychology, 71(3): 484-491.

Griffeth, R.W. 1985. 'Moderation of the effects of job enrichment by participation: A longitudinal field experiment,' Organizational Behavior and Human Decision Processes, 35: 73-93.

Griffin, R.W. 1983. 'Objective and social sources of information in task redesign: A field experiment,' Administrative Science Quarterly, 28: 184-200.

Griffin, R.W. 1991. 'Effects of work redesign on employee perceptions, attitudes, and behaviors: A long-term investigation,' Academy of Management Journal, 34(2): $425-435$.

Hackman, J.R. \& Lawler, E.E. 1971. 'Employee reactions to job characteristics,' Journal of Applied Psychology Monograph, 55: 259-286.

Hackman, J.R. \& Oldham, G.R. 1974. The job diagnostic survey: An instrument for diagnosing the motivational potential of jobs. Technical Report no. 4. Department of Administrative Sciences. Yale University.

Hackman, J.R. \& Oldham, G.R. 1975. 'Development of the job diagnostic survey,' Journal of Applied Psychology, 60(2): 159-170

Hackman, J.R. \& Oldham, G.R. 1976. 'Motivation through the design of work: Test of a theory,' Organizational Behavior and Human Performance, 16(2): 250-279.

Hackman, J.R. \& Oldham, G.R. 1980. Work redesign. Philippines: Addison-Wesley.

Hackman, J.R., Pearce, J.L. \& Wolfe, J.C. 1978. 'Effects of changes in job characteristics on work attitudes and behaviors: A naturally occurring quasi-experiment,' Organizational Behavior and Human Performance, 21 : 289-304.

Harvey, R.J., Billings, R.S. \& Nilan, K.J. 1985. 'Confirmatory factor analysis of the job diagnostic survey: Good news and bad news,' Journal of Applied Psychology, 70: 461- 
468.

Hinton, M. \& Biderman, M. 1995. 'Empirically derived job characteristics measures and the motivating potential score,' Journal of Business and Psychology, 9(4): 355363.

Hochwarter, W.A., Zellars, K.L., Perrewé, P.L. \& Harrison, A.W. 1999. 'The interactive role of negative affectivity and job characteristics: Are high-NA employees destined to be unhappy at work?' Journal of Applied Social Psychology, 29(10): 2203-2218.

Hogan, E.A. \& Martell, D.A. 1987. 'A confirmatory structural equations analysis of the job characteristics model,' Organizational Behavior and Human Decision Processes, 39: 242-263.

Hunt, M., Head, T.C. \& Sorensen, P.F. 1982. 'Job characteristics, job satisfaction, motivation and the role of context variables: A study of hospital pharmacists,' Psychological Reports, 51: 394.

Idaszak, J.R., Bottom, W.P. \& Drasgow, F. 1988. 'A test of the measurement equivalence of the revised job diagnostic survey: Past problems and current solutions,' Journal of Applied Psychology, 73(4): 647-656.

Idaszak, J.R. \& Drasgow, F. 1987. 'A revision of the job diagnostic survey: Elimination of a measurement artifact,' Journal of Applied Psychology, 72: 461-468.

Jackson, P.R., Paul, L.J. \& Wall, T.D. 1981. 'Individual differences as moderators of reactions to job characteristics,' Journal of Occupational Psychology, 54: $1-8$.

James, L.R. \& Tetrick, L.E. 1986. 'Confirmatory analytic tests of three causal models relating job perceptions to job satisfaction,' Journal of Applied Psychology, 71(1): 7782.

Johns, G., Xie, J.L. \& Fang, Y. 1992. 'Mediating and moderating effects in job design,' Journal of Management, 18(4): $657-676$.

Katerberg, R., Hom, P.W. \& Hulin, C.L. 1979. 'Effects of job complexity on the reactions of part-time employees, Organizational Behavior and Human Performance,' 24:317-332.

Katz, R. 1978. 'The influence of job longevity on employee reactions to task characteristics,' Human Relations, 31(8): 703-725.

Kelly, J. 1992. 'Does job re-design theory explain jobredesign outcomes?' Human Relations, 45(8): 753-774.

Kemp, N.J. \& Cook, J.D. 1983. 'Job longevity and growth need strength as joint moderators of the task design - job satisfaction relationship,' Human Relations, 36(10): 883898.
Kulik, C.T., Oldham, G.R. \& Hackman, J.R. 1987. 'Work design as an approach to person - environment fit,' Journal of Vocational Behavior, 31: 278-296.

Kulik, C.T., Oldham, G.R. \& Langner, P.H. 1988. 'Measurement of job characteristics: Comparison of the original and the revised job diagnostic survey,' Journal of Applied Psychology, 73(3): 462-466.

Lee, R. \& Klein, A.R. 1982. 'Structure of the job diagnostic survey for public sector occupations,' Journal of Applied Psychology, 67: 515-519.

Lee, R., McCabe, D.J. \& Graham, W.K. 1983. 'Multivariate relationships between job characteristics and job satisfaction in the public sector: A triple cross-validation study,' Multivariate Behavioural Research, 18: 47-62.

Loher, B.T., Noe, R.A., Moeller, N.L. \& Fitzgerald, M.P. 1985. 'A meta-analysis of the relation of job characteristics to job satisfaction,' Journal of Applied Psychology, 70:280-289.

Maillet, L.J. 1984. 'Influence of perceived job enrichment and goal characteristics on employees' satisfaction, motivation, and performance,' Psychological Reports, 54: 131-137.

Maslow, A.H. 1943. 'A theory of human motivation,' Psychological Review, 50: 370-396.

Maslow, A.H. 1954. Motivation and personality. New York: Harper and Brothers.

Mathieu, J.E., Hofmann, D.A. \& Farr, J.L. 1993. 'Job perception-job satisfaction relations: An empirical comparison of three competing theories,' Organizational Behavior and Human Decision Processes, 56: 370-387.

Miner, J.B. 1980. Theories of organizational behavior. Hinsdale: Dryden Press.

Morrison, K.A. 1996. 'An empirical test of a model of franchisee job satisfaction,' Journal of Small Business Management, 27-41.

Munz, D.C., Huelsman, T.J., Konold, T.R. \& McKinney, J.J. 1996. 'Are there methodological and substantive roles for affectivity in job diagnostic survey relationships?' Journal of Applied Psychology, 81(6): 795-805.

Nel, P.S., Gerber, P.D., Van Dyk, P.S., Haasboek, G.D., Schultz, H.B., Sono, T. \& Werner, A. 2001. Human resources management. Fifth Edition. Cape Town: Oxford University Press.

O'Brien, G.E. 1982. 'Evaluation of the job characteristics theory of work attitudes and performance,' Australian Journal of Psychology, 34(3): 383-401.

Oldham, G.R. 1976. 'Job characteristics and internal 
motivation: The moderating effect of interpersonal and individual variables,' Human Relations, 29(6): 559-569.

Oldham, G.R. \& Brass, D.I. 1979. 'Employee reactions to an open-plan office: A naturally occurring quasiexperiment,' Administrative Science Quarterly, 24: 267284.

Oldham, G.R., Hackman, J.R. \& Pearce, J.L. 1976. 'Conditions under which employees respond positively to en-riched work,' Journal of Applied Psychology, 61(4):395-403.

Ondrack, D.A. \& Evans, M.G. 1986. 'Job enrichment and job satisfaction in quality of working life and nonquality of working life work sites,' Human Relations, 39(9): 871889.

Orpen, C. 1979. 'The effects of job enrichment on employee satisfaction, motivation, involvement, and performance: A field experiment,' Human Relations, 32: 189-217.

Orpen, C. 1983. Westernization as a moderator of the effect of job characteristics on employee reactions: An empirical study among black workers in South Africa. HSRC Report.

Pokorney, I., Gilmore, D. \& Beehr, T. 1980. 'Job diagnostic survey dimensions: Moderating effect of growth needs and correspondence with dimensions of job rating form,' Organizational Behavior and Human Performance, 26:222-237.

Renn, R.W. 1989. A holistic evaluation of the job characteristics model: A longitudinal structural equation analysis. Doctoral thesis. Georgia State University.

Renn, R.W. \& Vandenberg, R.J. 1995. 'The critical psychological states: An underrespresented component in job characteristics model research,' Journal of Management, 21(2): 279-303.

Repetti, R.L. \& Cosmas, K.A. 1991. 'The quality of the social environment at work and job satisfaction,' Journal of Applied Social Psychology, 21: 840-854.

Roberts, K.H. \& Glick, W.H. 1981. 'The job characteristics approach to task design: A critical review,' Journal of Applied Psychology, 66: 193-217.

Sims, H.P., Szilagyi, A.D. \& Keller, R.T. 1976. 'The measurement of job characteristics,' Academy of Management Journal, 19(2): 195-212.

Spector, P.E. 1985.'Higher-order need strength as a moderator of the job scope-employee outcome relationship: A metaanalysis,' Journal of Occupational Psychology, 58:119127.

Spector, P.E. \& Jex, S.M. 1991. 'Relations of job characteristics from multiple data sources with employee affect, absence, turnover intentions and health,' Journal of Applied Psychology, 76(1): 46-53.

Staw, B.M. \& Ross, J. 1985. 'Stability in the midst of change: A dispositional approach to job attitudes,' Journal of Applied Psychology, 70: 469-480.

Steers, R.M. \& Porter, L.W. 1991. Motivation and work behavior. Singapore: McGraw-Hill.

Stone, E.F. 1986. Job scope - job satisfaction and job scope job performance relationships. In Locke, E.A. (Ed.) Generalizing from laboratory to field settings. Lexington Books.

Stone, E.F. \& Porter, L.W. 1978. 'On the use of incumbent - supplied job characteristics data,' Perceptual and Motor Skills, 46: 751-758.

Taber, T.D., Beehr, T.A. \& Walsh, J.T. 1985. 'Relationships between job evaluation ratings and self-ratings of job characteristics,' Organizational Behavior and Human Decision Processes, 35: 27-45.

Taber, T.D. \& Taylor, E. 1990. 'A review and evaluation of the psychometric properties of the job diagnostic survey,' Personnel Psychology, 43: 467-500.

Teas, R.K. 1981. 'A test of a model of department store salespeople's job satisfaction,' Journal of Retailing, 57: 3-26.

Teas, R.K. 1982. 'Performance - reward instrumentalities and the motivation of retail salespeople,' Journal of Retailing, 58: $4-26$.

Terborg, J.R. \& Davis, G.A. 1982. 'Evaluation of a new method for assessing change to planned job redesign as applied to Hackman and Oldham's job characteristic model,' Organizational Behavior and Human Performance, 29: 112-128.

Thierry, H.K. \& Koopman-Iwema, A.M. 1984. Motivation and satisfaction. In Drenth, P.J.D., Thierry, H., Willems, P.J. \& de Wolff, C.J. (Eds.) Handbook of work and organizational psychology. John Wiley.

Turner, A.N. \& Lawrence, P.R. 1965. Industrial jobs and the worker. Boston: Harvard University Press.

Umstot, D.D., Bell, C.H. \& Mitchell, T.R. 1976. 'Effects of job enrichment and task goals on satisfaction and productivity: Implications for job design,' Journal of Applied Psychology, 61: 379-394.

Vecchio, R.P. 1980. 'Worker alienation as a moderator of the job quality - job satisfaction relationship: The case of racial differences,' Academy of Management Journal, 23(3): 479-486.

Vecchio, R.P. \& Keon, T.L. 1981. 'Predicting employee 
satisfaction from congruency among individual need, job design, and system structure,' Journal of Occupational Behavior, 2: 283-292.

Wahba, M.A. \& Bridwell, L.G. 1983. Maslow reconsidered. In Steers, R.M. \& Porter, L.W. (Eds.) Motivation and work. USA: McGraw Hill.

Wall, T.D. \& Clegg, C.W. 1981. 'A longitudinal field study of group work redesign,' Journal of Occupational Behaviour, 2: $31-49$.

Wall, T.D., Clegg, C.W. \& Jackson, P.R. 1978. 'An evaluation of the job characteristics model,' Journal of Occupational Psychology, 51: 183-196.

Wall, T.D. \& Martin, R. 1987. Job and work design. In Cooper, C.L. \& Robertson, I.T. (Eds.) International review of industrial and organizational psychology. John Wiley.

Wiesner, R. \& Vermeulen, L.P. 1997. 'Revised job design practices for future South African organizations,' South African Journal of Economic and Management Sciences, 21: 175-196.

Wright, T.A. \& Staw, B.M. 1999. 'Affect and favorable work outcomes: two longitudinal tests of the happy - productive worker thesis,' Journal of Organizational Behavior, 20: 123.

Yeh, Q. 1996. 'Relating management practices of job characteristics of R\&D: The case of Taiwan,' Asia Pacific Journal of Management, 13(1): 1-18. 


\section{Appendix A}

\section{The Revised Job Diagnostic Survey}

The Job Diagnostic Survey is used to diagnose jobs and how people react to them. The questionnaire is useful in determining how jobs can be better designed, by obtaining information about how people react to different kinds of jobs.

On the following pages you will find several different questions relating to your job. Specific instructions are given at the start of each section. The questions are designed to obtain your perceptions of your job and your reactions to it. There are no trick questions. Your individual answers will be kept completely confidential. Please answer each item as honestly and frankly as possible.

Thank you for your co-operation.

\section{SECTION ONE}

This part of the questionnaire asks you to describe your job, as objectively as you can.

Please do not use this part of the questionnaire to show how much you like or dislike your job. Questions about that will come later. Instead, try to make your descriptions as accurate and as objective as you possibly can.

A sample question is given below:

A. To what extent does your job require you to work with mechanical equipment?

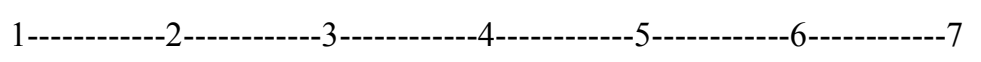

\begin{tabular}{|c|c|c|}
\hline $\begin{array}{l}\text { Very little; the job requires } \\
\text { almost no contact with } \\
\text { mechanical equipment of any }\end{array}$ & Moderately. & $\begin{array}{l}\text { Very much; the job requires } \\
\text { almost constant work with } \\
\text { mechanical equipment. }\end{array}$ \\
\hline
\end{tabular}

kind.

If, for example, your job requires you to work with mechanical equipment a good deal of the time - but also requires some paperwork - you might indicate a number 6 on the separate answer sheet.

If you do not understand these instructions, please ask for assistance.

1 How much autonomy is there in your job? That is, to what extent does your job permit you to decide on your own how to go about doing the work?

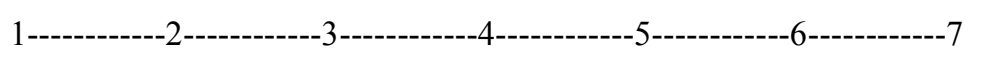

Very little; the job gives me almost no personal 'say' about how and when the work is done.
Moderate autonomy; many things are standardised and not under my control, but I can make some decisions about the work.
Very much; the job gives me almost complete responsibility for deciding how and when the work is done.

2 To what extent does your job involve doing a 'whole' and identifiable piece of work? That is, is the job a complete piece of work that has an obvious beginning and end? Or is it only a small part of the overall piece of work, which is finished by other people or by automatic machines?

My job is only a tiny part of the overall piece of work; the results of my activities cannot be seen in the final product or service.

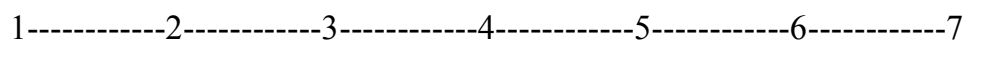

My job is a moderate-sized 'chunk' of the overall piece of work; my own contribution can be seen in the final outcome.
My job involves doing the whole piece of work, from start to finish; the results of my activities are easily seen in the final product or service. 
3 How much variety is there in your job? That is, to what extent does the job require you to do many different things at work, using a variety of your skills and talents?

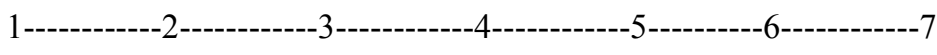

Very little; the job requires me to do the same routine

Moderate variety.

Very much; the job requires me to do many different things, using a number of different skills and talents.

4 In general, how significant or important is your job? That is, are the results of your work likely to significantly affect the lives or well-being of other people?

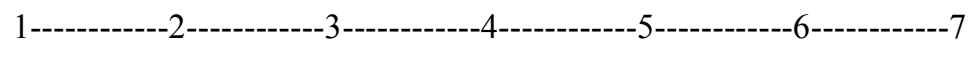

Not very significant; the outcomes of my work are not

Moderately significant.

Highly significant; the outcomes of my work can affect other people in very likely to have important important ways.

effects on other people.

5 To what extent does doing the job itself provide you with information about your work performance? That is, does the actual work itself provide clues about how well you are doing - aside from any 'feedback' co-workers or supervisors may provide?

Very little; the job itself is set up so that I could work forever without finding out how well I am doing.

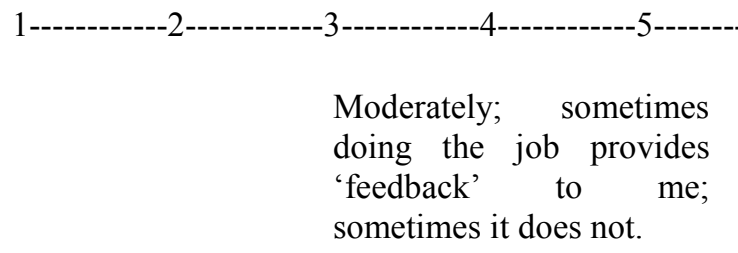

Moderately; sometimes

'feedback' to me;

sometimes it does not.
Very much; the job is set up so that I get almost constant 'feedback' as I work about how well I am doing.

\section{SECTION TWO}

Listed below are a number of statements which could be used to describe a job.

Please indicate whether each statement is an accurate or an inaccurate description of your job.

Once again, please try to be as objective as you can in deciding how accurately each statement describes your job - regardless of whether you like or dislike your job.

Write a number on the separate answer sheet based on the following scale:

How accurate is the statement in describing your job?

$\begin{array}{lllllll}1 & 2 & 3 & 4 & 5 & 6 & 7 \\ \text { Very } & \text { Mostly } & \text { Slightly } & \text { Uncertain } & \text { Slightly } & \text { Mostly } & \text { Very } \\ \text { Inaccurate } & \text { Inaccurate } & \text { Inaccurate } & & \text { Accurate } & \text { Accurate } & \text { Accurate }\end{array}$

1. The job requires me to use a number of complex or high-level skills.

2. The job is arranged so that I can do an entire piece of work from beginning to end.

3. Just doing the work required by the job provides many chances for me to figure out how well I am doing. 
4. The job allows me to use a number of complex or high-level skills.

5. This job is one where a lot of other people can be affected by how well the work gets done.

6. The job gives me a chance to use my personal initiative and judgement in carrying out the work.

7. The job provides me with the chance to completely finish the pieces of work that I begin.

8. After I finish a job, I know whether I performed well.

9. The job gives me considerable opportunity for independence and freedom in how I do the work.

10.The job itself is very significant and important in the broader scheme of things.

\section{SECTION THREE}

Now please indicate how you personally feel about your job.

Each of the statements below is something that a person might say about his or her job. Please indicate your own personal feelings about your job by indicating to what extent you agree with each of the statements.

Write a number on the separate answer sheet based on this scale:

How much do you agree with the statement?

$\begin{array}{lllllll}1 & 2 & 3 & 4 & 5 & 6 & 7 \\ \text { Disagree } & \text { Disagree } & \text { Disagree } & \text { Neutral } & \text { Agree } & \text { Agree } & \text { Agree } \\ \text { Strongly } & & \text { Slightly } & & \text { Slightly } & & \text { Strongly }\end{array}$

1. My opinion of myself goes up when I do this job well.

2. Generally speaking, I am very satisfied with this job.

3. I feel a great sense of personal satisfaction when I do this job well.

4. I seldom think of quitting this job.

5. I feel good and happy when I discover that I have performed well on this job.

6. I am generally satisfied with the kind of work I do in this job. 
7. My own feelings are generally affected by how well I do in this job.

\section{SECTION FOUR}

Now please indicate how satisfied you are with each aspect of your job listed below.

Once again, indicate on the separate answer sheet the appropriate number for each statement:

How satisfied are you with this aspect of your job?

$\begin{array}{lllllll}1 & 2 & 3 & 4 & 5 & 6 & 7 \\ \text { Extremely } & \text { Dissatisfied } & \text { Slightly } & \text { Neutral } & \text { Slightly } & \text { Satisfied } & \text { Extremely } \\ \text { Dissatisfied } & & \text { Dissatisfied } & & \text { Satisfied } & & \text { Satisfied }\end{array}$

1. The amount of personal growth and development I get in doing my job.

2. The feeling of worthwhile accomplishment I get from doing my job.

3. The amount of independent thought and action I can exercise in my job.

4. The amount of challenge in my job.

\section{SECTION FIVE}

Now please think of the other people in your organization who hold the same job that you do. If no one has exactly the same job as you, think of the job which is most similar to yours.

Please think about how accurately each of the statements describes the feelings of those people about the job.

It is quite all right if your answers here are different from when you described your own reactions to the job. Often different people feel quite differently about the same job.

Once again indicate on the separate answer sheet a number based on this scale:

How much do you agree with the statement?

\begin{tabular}{|c|c|c|c|c|c|c|}
\hline 1 & 2 & 3 & 4 & 5 & 6 & 7 \\
\hline Disagree & Disagree & Disagree & Neutral & Agree & Agree & Agree \\
\hline Strongly & & Slightly & & Slightly & & Strongly \\
\hline
\end{tabular}

1. Most people in this job feel a great sense of personal satisfaction when they do the job well.

2. Most people in this job are very satisfied with the job. 
3. People in this job seldom think of quitting.

4. Most people in this job feel good or happy when they find that they have performed the work well.

The Revised Job Diagnostic Survey Scoring Procedure

The job characteristics are scored across the following items in each respective section of the revised JDS, according to the following scheme:

\begin{tabular}{|l|l|}
\hline Skill variety: & Section One, question 3; Section Two, statements 1 and 4 \\
\hline Task identity: & Section One, question 2; Section Two, statements 2 and 7 \\
\hline Task significance: & Section One, question 4; Section Two, statements 5 and 10 \\
\hline Autonomy: & Section One, question 1; Section Two, statements 6 and 9 \\
\hline Feedback: & Section One, question 5; Section Two, statements 3 and 8 \\
\hline
\end{tabular}

Subsequently, an average score is computed for each of the job characteristics. The Motivating Potential Score (MPS) represents the sum of the five respective average job characteristic scores.

The personal outcomes are scored across the following items in each respective section of the revised JDS according to the following scheme:

\begin{tabular}{|l|l|}
\hline \multirow{2}{*}{ Internal work motivation: } & Section Three, $\quad$ statements $1,3,5$ and 7 \\
\cline { 2 - 3 } & Section Five, $\quad$ statements 1 and 4 \\
\hline \multirow{2}{*}{ General job satisfaction: } & Section Three, $\quad$ statements 2,4 and 6 \\
\cline { 2 - 3 } & Section Five, $\quad$ statements 2 and 3 \\
\hline Growth satisfaction: & Section Four, $\quad$ statements $1,2,3$ and 4 \\
\hline
\end{tabular}

Subsequently an average score is computed for each of the personal outcomes. 